Space shuttle

\title{
Pentagon gains ground in battle for alternative
}

Washington

DESPITE a near-perfect maiden flight by the space shuttle orbiter Discovery last week, doubts over the shuttle's commercial prospects seem to be increasing. The shuttle successfully placed all its satellites into orbit, and the crew again demonstrated the possibilities of in-flight maintenance. But the day before Discovery touched down in California, an expert panel of the US National Research Council told Congress it was "not clear" that the shuttle would ever be competitive with an expendable launcher for military payloads and agreed with the air force's argument that a new launch vehicle would provide it with greater operational flexibility.

This leaves the National Aeronautical and Space Administration (NASA) with a major problem, because NASA had been counting on the military to pay for more than one third of projected future shuttle flights. If the US Air Force insists on developing its own expendable launcher for some of these flights, NASA may well have to increase its prices to civilian customers.

The National Research Council, the research arm of the National Academy of Sciences, was asked by appropriations committees of both houses of Congress to compare options for expendable launch vehicles capable of lifting large payloads into orbit. Its report echoes previous criticisms of the shuttle - main engine and fuel pump performance are still below specification, turn-around times are still too long and, says the committee, "a sustained engineering programme will be required to realize the full benefit" of the shuttle concept.

The air force has been unhappy with the shuttle for some time. Apart from the question of reliability, the Department of Defense has been concerned about the limited number of launch sites and the security difficulties should it wish to launch a sensitive satellite "without the public exposure that has become the norm in NASA flight operations". The research council panel also points out that in time of crisis the shuttle would have to overfly Soviet territory in order to put a satellite into a polar orbit suitable for reconnaissance: here, an unmanned launcher offers obvious advantages. And commercial companies might be happier if the Department of Defense were less likely to requisition planned shuttle flights, as it has the right to do.

The panel examined three possible expendable launchers being considered by the Department of Defense - the Titan 34D7/Centaur, the Atlas II and the SRB-
$\mathrm{X}$, which is derived from the shuttle. All are based on existing technology. Any of these would be capable of meeting immediate requirements but none offers the possibility of expansion to carry loads much heavier than 10,000 pounds to geosynchronous orbit, the panel concludes. The cost of developing one of the alternatives would be around $\$ 2,000$ million.

The research council panel avoids addressing in detail how the prospect of a new competitor to the shuttle would affect NASA finances. NASA at present charges its customers only "out-of-pocket

expenses", although there is pressure for it to move to a full-cost policy. But already the European Ariane launcher " appears to be competitive"' with the shuttle.

While apparently accepting all the military's arguments for a new expendable launcher, the National Research Council panel stops short of giving the project an unconditional endorsement. The main need, it concludes, is for further study of a new class of heavyweight launch vehicle capable of taking payloads of up to 450,000 pounds into low Earth orbit. Both NASA and the air force are already working on plans for such a system, thought likely to be necessary for President Reagan's "strategic defence initiative", better known as Star Wars. Such a system could be designed using motors developed for the shuttle programme with the aim of reducing costs without loss of reliability.

Tim Beardsley

\section{British aerospace}

\section{Per atmosphaera ad astra}

A BRITISH space shuttle? Surely a joke? Perhaps, perhaps not. A study by British Aerospace of a new concept for the launch of large payloads (up to 7 tonnes) into low Earth orbit comes as the British Government finds itself under increasing pressure from its high-technology companies and its European Space Agency partners to make a positive commitment to space or pass up for ever the chance to keep a presence on the "high frontier".

The new concept, dubbed HOTOL (Horizontal Take-Off and Land Satellite Launcher), is of a vehicle of aircraft type with the ability to take off horizontally and land on a conventional runway. The vehicle would use a combination of air breathing and rocket propulsion.

An ideal re-usable launch vehicle, says British Aerospace, should have no expendable parts (unlike the US space shuttle), should be capable of repeated operations with a minimum turn-around between missions, accommodate payloads in the 4-7 tonnes range and, if necessary, should be capable of unmanned operation.

At present vertical take-off into Earth orbit is impossible because even the highest-performance chemical fuels give a single-stage rocket insufficient impulse. A two-stage lift is essential, so that expensive equipment is irrevocably lost in re-entry or at sea.

British Aerospace proposes to overcome this apparently insurmountable difficulty by economizing on the supply of liquid oxygen, which may account for 85 per cent of the propellant mass of a booster rocket. If air scooped from the atmosphere were to supplement a rocket's supplies of liquid oxygen during the early phases of flight, its dead weight might be substantially reduced. Add wings for additional lift and there it is - HOTOL. British Aerospace believes the system capable of revolution-

\section{alizing the space industry.}

It is unlikely that Britain would have the resources to undertake such a major project on its own. If life were to be breathed into the idea, a collaborative effort, perhaps with other European countries, would seem the most prudent course to take.

It is just such a collaboration that European ministers are now pressing Britain to join, chiefly in the form of a European consortium to take part in the US manned space platform. Britain would

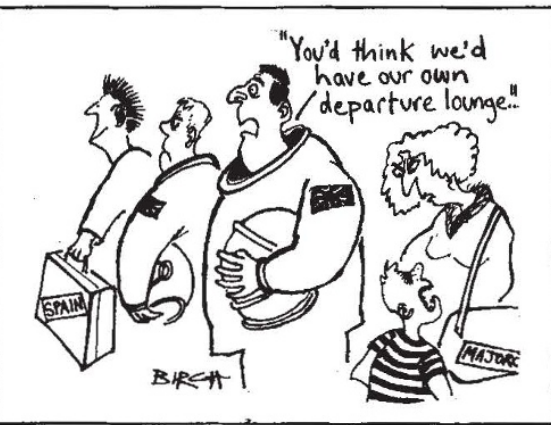

be expected to contribute an extra $£ 15$ million a year compared with its present spending of just $£ 80$ million a year (and France's $£ 400$ million), principally for membership of the European Space Agency.

British Aerospace is eager for government support for its space effort. But in the realm of fact rather than fancy, the company has announced a contract, from the US corporation Scott Science and Technology Inc., to design a Satellite Transfer Vehicle needed to carry satellites from shuttle orbits to geosynchronous orbit. The vehicle will be propelled by liquid fuels which, as well as being more efficient than solid fuel, will allow a range of burn strategies tailored to individual missions.

Marcus Chown 